\title{
ÜBERSICHT DER SAMMLUNGEN.
}

Raum 1. Ostpreußen, Pommern, Niedersachsen, Friesen,

Seite

Vierlande $\ldots \ldots \ldots \ldots \ldots \ldots \ldots \ldots \ldots \ldots \ldots \ldots$ 10-14

Ostfriesische Stube....................14-15

" 3. Schleswig-Holstein, Oldenburg, Hannover (Vir-

chow-Stube $) \ldots \ldots \ldots \ldots \ldots \ldots \ldots \ldots \ldots \ldots \ldots$ 15-17

Vergleichende Sammlungen:

Spielzeug.$\ldots \ldots \ldots \ldots \ldots \ldots \ldots \ldots \ldots \ldots \ldots \ldots$

4. Schlesische Holzstube ................ 17-18

Vergleichende Sammlungen:

Geräte zur Landwirtschaft und Viebzucht ...... 18-19

Braunschweig, Hannover ................ 19

Schaumburg-Lippe, Rheinland, Westfalen ...... 19-21

Hessen........................... 21

n 4-5. Prov. Sachsen, Thtiringen ............ 21-22

n 5. Mark Brandenburg und Lausitz ............ 23-24

Vergleichende Sammlungen:

Kerbhölzer, Holzkalender, Stäbe .......... 24-25

6. Spreewälder Stube ................... 25-27

Vergleichende Sammlungen:

Bauerntöpferei .................... 27-29

Elsaß-Lothringen ................. 29-30

n 9. Schweiz ........................ 30-31

Vergleichende Sammlungen:

Beleuchtungsgerät $\ldots \ldots \ldots \ldots \ldots \ldots \ldots \ldots \ldots \ldots, 31-32$

Baden, Wurttemberg.................. 32-33

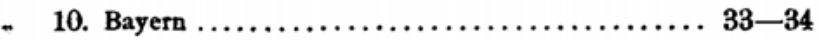

Vergleichende Sammlungen:

Deckengehănge...................... 34 
Seice

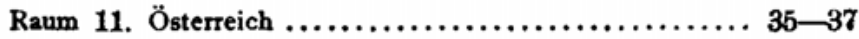

- 12. Vergleichende Sammlungen:

Spinnen und Weben.................. 37-39

n 13. Vergleichende Sammlungen:

Votive (Opfer) ................... 39-41

》 14. Vergleichende Sammlungen:

Hausmodelle ..................... 41-57

Totenkultus ...................... $57-58$

Volksglaube, Volksmedizin, Volksbrauch...... 58-61

Festgerăte und Gebăcke.................61-66

Masken ..........................64 64

Hofgebăude. Hollăndische Stube................66-69

Waagensammlung...................69

Luneburger Stube mit Zunftgerăten ........6 69-70 